\title{
Alexithymia and fear of pain independently predict heat pain intensity ratings among undergraduate university students
}

\author{
Joel Katz $\mathrm{PhD}^{1,2}$, Andrea L Martin $M A^{1}$, M Gabrielle Pagé $B A^{1}$, Vincent Calleri $M A^{2}$
}

J Katz, AL Martin, MG Pagé, V Calleri. Alexithymia and fear of pain independently predict heat pain intensity ratings among undergraduate university students. Pain Res Manage 2009;14(4):299-305.

BACKGROUND: Alexithymia is a disturbance in awareness and cognitive processing of affect that is associated with over-reporting of physical symptoms, including pain. The relationship between alexithymia and other psychological constructs that are often associated with pain has yet to be evaluated.

OBJECTIVES: The present study examined the importance of alexithymia in the pain experience in relation to other integral psychological components of Turk's diathesis-stress model of chronic pain and disability, including fear of pain, anxiety sensitivity, pain avoidance and pain catastrophizing.

METHODS: Heat pain stimuli, using a magnitude estimation procedure, and five questionnaires (Anxiety Sensitivity Index, Fear of Pain Questionnaire III, Pain Catastrophizing Scale, avoidance subscale of the Pain Anxiety Symptoms Scale-20 and Toronto Alexithymia Scale-20) were administered to 67 undergraduate students ( 44 women) with a mean $( \pm$ SD) age of $20.39 \pm 3.77$ years.

RESULTS: Multiple linear regression analysis revealed that sex, fear of pain and alexithymia were the only significant predictors of average heat pain intensity $\left(\mathrm{F}[6,60]=5.43 ; \mathrm{R}^{2}=0.35 ; \mathrm{P}=0.008\right)$, accounting for $6.8 \%$, $20.0 \%$ and $9.6 \%$ of unique variance, respectively. Moreover, the difficulty identifying feelings and difficulty describing feelings subscales, but not the externally oriented thinking subscale of the Toronto Alexithymia Scale-20 significantly predicted average heat pain intensity.

CONCLUSIONS: Individuals with higher levels of alexithymia or increased fear of pain reported higher average pain intensity ratings. The relationship between alexithymia and pain intensity was unrelated to other psychological constructs usually associated with pain. These findings suggest that difficulties with emotion regulation, either through reduced emotional awareness via alexithymia or heightened emotional awareness via fear of pain, may negatively impact the pain experience.

Key Words: Alexithymia; Fear of pain; Heat pain stimulation; Pain intensity; Undergraduates

\section{L'alexithymie et la crainte de la douleur prédisent de manière indépendante l'intensité de la réponse douloureuse aux stimuli thermiques ressentie chez des étudiants de premier cycle universitaire}

\begin{abstract}
HISTORIQUE : L'alexithymie est un trouble affectant la conscience et le traitement cognitif de l'affect associé à une exagération des symptômes physiques ressentis, dont la douleur. Le lien entre l'alexithymie et d'autres construits psychologiques souvent associés à la douleur n'a pas encore été évalué.

OBJECTIF : La présente étude a analysé l'importance de l'alexithymie dans l'expérience de la douleur en lien avec d'autres construits psychologiques du modèle diathèse-stress de Turk sur la douleur chronique et l'invalidité, y compris la crainte de la douleur, la sensibilité à l'anxiété, l'évitement de la douleur et le catastrophisme lié à la douleur.

MÉTHODE : Les auteurs ont administré à 67 étudiants de premier cycle (44 femmes) âgés en moyenne ( \pm É.-T.) de 20,39 \pm 3,77 ans des stimuli douloureux thermiques en utilisant une technique d'évaluation de l'intensité et cinq questionnaires (l'Anxiety Sensitivity Index, le Fear of Pain Questionnaire III, la Pain Catrastrophizing Scale, la sous-échelle d'évitement de la Pain Anxiety Symptoms Scale-20 et la Toronto Alexithymia Scale-20).

RÉSULTATS : L'analyse de régression linéaire multiple a révélé que le sexe, la crainte de la douleur et l'alexithymie étaient les seuls prédicteurs significatifs de l'intensité moyenne de la douleur d'origine thermique $\left(\mathrm{F}[6,60]=5,43, \mathrm{r}^{2}=0,35, \mathrm{p}=0,008\right)$, représentant $6,8 \%, 20,0 \%$ et $9,6 \%$ de la variance unique, respectivement. De plus, les sous-échelles portant sur la difficulté d'identifier les sentiments et la difficulté de décrire les sentiments, contrairement à la sous-échelle portant sur les pensées concernant la réalité externe de la Toronto Alexithymia Scale-20, ont permis de prédire de façon significative l'intensité moyenne de la douleur d'origine thermique.

CONCLUSION : Les sujets présentant un degré plus élevé d'alexithymie ou une crainte plus grande de la douleur ont en moyenne estimé l'intensité de la douleur plus marquée. Le lien entre l'alexithymie et l'intensité de la douleur ne s'est pas révélé associé à d'autres construits psychologiques habituellement liés à la douleur. Ces conclusions donnent à penser que certains problèmes de régulation émotionnelle peuvent avoir un impact négatif sur l'expérience de la douleur, par l'entremise d'une sensibilité émotionnelle émoussée causée par l'alexithymie, ou d'une sensibilité émotionnelle accrue due à la crainte de la douleur.
\end{abstract}

Research has shown that patients with chronic pain have higher levels of alexithymia than healthy controls, and alexithymia is associated with over-reporting physical symptoms (eg, somatic complaints, anxiety, and hypochondriasis) (6). Research conducted on healthy subjects has also demonstrated an association between alexithymia and increased pain intensity and sensitivity in laboratory studies of experimentally induced pain (7-9) and in a community sample of pain has become a focus of intense research. Alexithymia is a multidimensional construct $(1,2)$ that refers to cognitive and emotional disturbances (3) characterized by four attributes - problems recognizing and explaining emotions, problems distinguishing between emotional and physical sensations, restricted imagination, and externally focused and concrete cognitive style (3-5).
${ }^{1}$ Department of Psychology; ${ }^{2}$ School of Kinesiology and Health Science, Faculty of Health, York University, Toronto, Ontario

Correspondence: Dr Joel Katz, Department of Psychology, Behavioral Sciences Building, York University, 4700 Keele Street, Toronto, Ontario

M3J 1P3. Telephone 416-736-2100 ext 40557, fax 416-736-5814, e-mail jkatz@yorku.ca 
individuals undergoing venipuncture for blood donation (10).

Results from these studies highlight the importance of alexithymia in the pain experience. However, most research examining pain and alexithymia has been conducted in isolation from other psychological factors (11-13) recognized as integral to the pain experience. Research supports the importance of anxiety sensitivity $(14,15)$, fear of pain and pain anxiety (16-19), pain avoidance $(20,21)$, and pain catastrophizing $(22,23)$ in the expression of pain and pain-related disability. These constructs have been the focus of recent models of pain, such as the diathesis-stress model of chronic pain and disability (24).

According to this model (24), individuals who are high in anxiety sensitivity (diathesis) and who are exposed to a painful trauma or event (stress) are likely to develop chronic pain and disability through well-articulated cognitive and emotional processes involving fear and avoidance (eg, fear of pain, catastrophizing, self-efficacy, and escape-avoidance) (25). Despite the growing body of research demonstrating the relationship between alexithymia and pain, there is very little integration of these findings with existing models of pain, such as Turk's diathesisstress model (24). An exception is the study by Lumley et al (26), which examined the relationship between alexithymia, self-efficacy, catastrophizing, depression, and pain severity and impairment in patients with chronic myofascial pain. Alexithymia showed a moderate to strong correlation with self-efficacy, catastrophizing, and depression, and was also associated with pain affect and impairment, but not with pain sensitivity (26).

The objective of the current study was to examine the relationship between alexithymia and integral components of the pain experience highlighted in Turk's diathesis-stress model of chronic pain and disability (24). The relationships among alexithymia, fear of pain, anxiety sensitivity, pain avoidance, catastrophizing, sex, and heat pain intensity were assessed in a sample of undergraduate university students.

\section{METHODS}

\section{Participants}

The study sample comprised 67 undergraduate students (44 women and 23 men) 17 to 45 years of age, who had a mean $( \pm$ SD) age of 20.39 \pm 3.77 years, and were proficient in English. Individuals received course credit for their participation.

\section{Heat pain stimuli and subjective pain ratings}

Thermal stimuli were delivered using a Peltier thermode with a skin contact surface of $16 \mathrm{~mm}^{2}$ (TSA-III NeuroSensory Analyzer; Medoc Ltd, Israel). This computerized device is capable of generating heat or cold stimuli that range from approximately $0^{\circ} \mathrm{C}$ to $50^{\circ} \mathrm{C}$. Pressing a button stops the rise or drop in temperature and the thermode rapidly returns to room temperature at a rate of $10^{\circ} \mathrm{C} / \mathrm{s}$. Even at the extreme high $\left(50^{\circ} \mathrm{C}\right)$ and low $\left(0^{\circ} \mathrm{C}\right)$ temperatures, the thermode does not damage the skin, although participants may temporarily feel sensitive at the site where the thermode is applied.

The contact thermode was applied to the ventral aspect of the participant's nondominant forearm and affixed in place with a Velcro strap (Velcro USA Inc). Consistent with previous work in magnitude estimation of thermal stimuli (27), four suprapain threshold heat stimuli $\left(46^{\circ} \mathrm{C}, 47^{\circ} \mathrm{C}, 48^{\circ} \mathrm{C}\right.$, and $49^{\circ} \mathrm{C}$ ) were administered in random order. All trials began at a baseline temperature of $32^{\circ} \mathrm{C}$, increased at a rate of $4^{\circ} \mathrm{C} / \mathrm{s}$ and remained at the preset peak temperature for a duration of $5 \mathrm{~s}$. A $30 \mathrm{~s}$ interval was maintained between successive stimuli to avoid sensitization of cutaneous receptors. During the $5 \mathrm{~s}$ period when the thermode reached its peak temperature, participants were asked to rate the intensity of the pain they experienced on a numerical rating scale (NRS) ranging from no pain at all $(0)$ to the most intense pain imaginable (100). These temperatures were selected to be consistent with previous work (27) and to ensure that these stimuli were above the mean heat pain threshold (as previously established in these subjects; data not shown).

\section{Questionnaires}

Anxiety Sensitivity Index: The Anxiety Sensitivity Index (ASI) (28) is a widely used, 16-item scale that measures concerns that anxiety and anxiety-related symptoms will lead to harmful negative consequences. Each item is rated on a fivepoint scale ranging from 0 (very little) to 4 (very much). The ASI yields a total score and three factor analytic-derived subscale scores, including fear of somatic symptoms/physical concerns, fear of cognitive symptoms/mental incapacitation concerns, and fear of publicly observable symptoms/social concerns (29). The ASI demonstrates good test-retest reliability $(\mathrm{r}=0.72)$ and research demonstrates some evidence for the discriminant validity of the three subscales among anxiety disorder outpatients (30). The internal consistency of the ASI in the present study was excellent (alpha $=0.87$ ).

Pain Catastrophizing Scale: Pain catastrophizing is characterized by unrealistic beliefs that the current situation will lead to the worst possible pain outcome (31), negative thoughts about the future and self (24), and "an exaggerated negative 'mental set' brought to bear during actual or anticipated pain experience" (32). The Pain Catastrophizing Scale (PCS) (33) consists of 13 items describing thoughts and feelings that individuals may experience when they are in pain. Each item is rated on a five-point scale ranging from 0 (not at all) to 4 (all the time). The PCS yields a total score and three subscale scores assessing rumination, magnification, and helplessness. The PCS demonstrates adequate to excellent internal consistency in community (alpha $=0.88$ to 0.95$)$ and pain outpatient samples (alpha $=$ 0.75 to 0.92 ) (34). The PCS has moderate convergent validity; the correlation coefficient between the PCS and a self-report measure of anxiety is $r=0.32$ and negative affectivity is $r=0.70$ (33). The PCS shows good test-retest reliability at six $(r=0.75)$ and $10(\mathrm{r}=0.70)$ weeks (33). The internal consistency of the PCS in the present study was excellent (alpha $=0.92)$.

Pain Anxiety Symptoms Scale-20: The Pain Anxiety Symptoms Scale-20 (PASS-20) (35) is a shortened 20-item version of the original 40-item PASS (36) designed to assess fear and anxiety responses specific to pain. The PASS-20 consists of four five-item subscales, including cognitive anxiety responses, escape and avoidance, fearful thinking, and physiological anxiety responses. Each item is rated on a six-point scale ranging from 0 (never) to 5 (always), with total scores ranging from 0 to 100 . The PASS-20 has been shown to have good internal consistency (alpha $=0.81)$ and good convergent validity with the original 40-item PASS $(r=0.95)$ (35). Concurrent validity of the PASS-20 is demonstrated through its moderate to high correlations with related measures such as anxiety sensitivity (ASI; $r=0.56$ ), fear of pain (Fear of Pain 
TABLE 1

Descriptive statistics and zero-order correlations among variables $(n=67)$

\begin{tabular}{|c|c|c|c|c|c|c|c|c|c|c|}
\hline & 1 & 2 & 3 & 4 & 5 & 6 & 7 & 8 & 9 & 10 \\
\hline 1. NRS-IN & $47.6 \pm 23.0$ & & & & & & & & & \\
\hline 2. FPQ-III & $0.412^{* *}$ & $81.6 \pm 15.0$ & & & & & & & & \\
\hline 3. ASI & $0.306^{*}$ & $0.392^{* *}$ & $33.1 \pm 8.8$ & & & & & & & \\
\hline 5. PCS & 0.101 & 0.088 & $0.250^{*}$ & $0.503^{* *}$ & $18.2 \pm 11.3$ & & & & & \\
\hline 6. TAS-20 & $0.367^{* *}$ & 0.065 & $0.257^{*}$ & 0.156 & $0.277^{*}$ & $46.6 \pm 10.8$ & & & & \\
\hline 7. TAS-F1 & $0.278^{*}$ & 0.045 & $0.348^{* *}$ & 0.163 & $0.429^{* *}$ & $0.788^{* *}$ & $14.76 \pm 5.02$ & & & \\
\hline 9. TAS-F3 & $0.266^{*}$ & 0.121 & 0.111 & 0.205 & 0.057 & $0.670^{* *}$ & 0.175 & $0.422^{* *}$ & $18.90 \pm 4.50$ & \\
\hline 10. SEX & 0.197 & -0.240 & 0.167 & -0.026 & -0.001 & 0.133 & 0.079 & -0.019 & $0.249^{*}$ & 0.34 \\
\hline
\end{tabular}

SEX is a coded variable $\left(0=\right.$ female, $1=$ male). Means $\pm S D$ s are reported on the diagonal. ${ }^{*} P<0.05 ;{ }^{*} P<0.01$. ASI Total score on the Anxiety Sensitivity Index; FPQ-III Total score on the Fear of Pain Questionnaire III; NRS-IN Numerical rating scale, pain intensity (0 to 100); PASS-AVO: Total score on the Avoidance subscale of the Pain Anxiety Symptoms Scale-20; PCS Total score on the Pain Catastrophizing Scale; TAS-20 Total score on the Toronto Alexithymia Scale-20; TAS-F1 Total score on the difficulty identifying feelings subscale of the TAS-20; TAS-F2 Total score on the difficulty describing feelings subscale of the TAS-20; TAS-F3 Total score on the externally oriented thinking subscale of the TAS-20

Questionnaire III [FPQ-III]; $\mathrm{r}=0.53)$, and pain catastrophizing (PCS; $r=0.38$ ) (37). The internal consistency of the PASS-20 in the present study was excellent $($ alpha $=0.93)$. Consistent with previous research $(38,39)$, the escape and avoidance subscale of the PASS-20 (PASS-AVO) was used as a measure of pain avoidance.

FPQ-III: The FPQ-III (40) is a 30 -item self-report measure designed to assess fear of pain in nonchronic pain populations. The FPQ-III assesses fear of severe pain, fear of minor pain, and fear of procedural pain due to medical interventions. Each item is rated on a five-point scale ranging from 1 (not at all) to 5 (extreme). The FPQ-III has good internal consistency (alpha = 0.88 to 0.92$)$ and test-retest reliability ( $\mathrm{r}=0.69$ to 0.74$)$ at three-week follow-up (40). Furthermore, high fear of pain scores correlate significantly with avoidance/escape behaviour during a pain-relevant Behavioral Avoidance Test, suggesting predictive validity (40). The internal consistency of the FPQIII in the present study was excellent (alpha $=0.89)$.

Toronto Alexithymia Scale-20: Alexithymia is a construct that describes a personality style characterized by deficits in the subjective awareness and cognitive processing of affect (41). The Toronto Alexithymia Scale-20 (TAS-20) (42) is a 20-item self-report inventory that measures three dimensions of alexithymia - difficulty identifying feelings, difficulty describing feelings, and externally oriented thinking. Each item is rated on a five-point scale ranging from 1 (strongly disagree) to 5 (strongly agree). Total TAS-20 scores range from 20 to 100. The TAS-20 demonstrates good internal consistency (alpha $=0.70$ to 0.86$)(43)$ and test-retest reliability $(r=0.77)$ over a three-week period (42). The internal consistency of the TAS-20 in the present study was good (alpha = 0.80 ).

NRS for pain intensity: Pain intensity in response to the four heat pain stimuli was measured using a self-report NRS (44). The NRS consists of a series of numbers ranging from 0 ('not at all') to 100 ('the most pain imaginable'). Participants were asked to choose the number that best corresponded to the intensity of each heat pain stimulus. The NRS is commonly used in clinical settings (45) and is the preferred pain rating scale among patients (46). The NRS is highly correlated $(\mathrm{r}=0.94)$ with the visual analogue scale (45) and is sensitive to change following pharmacological interventions (44).

\section{Procedure}

The research study was reviewed and approved by the Human Participants Review Committee at York University (Toronto, Ontario). Following informed written consent, participants underwent thermal sensory testing and completed the ASI, PCS, PASS-20, FPQ-III, and TAS-20. The order of administration of questionnaires was randomized within participants. The order of thermal testing and questionnaire completion was counterbalanced across participants such that one-half of the participants underwent thermal testing and then completed the questionnaires, and the other one-half completed the questionnaires followed by the thermal testing.

\section{Descriptive statistics}

\section{RESULTS}

Means and SDs of each score are presented on the main diagonal of Table 1. Scores on the TAS-20, PCS, PASS-AVO, and FPQ-III were similar to those obtained in large community samples. Ten per cent of participants $(n=7)$ in the present study had scores on the TAS-20 above the cut-off score of 61 or greater that corresponds with clinical levels of alexithymia (47). Scores on the ASI were higher compared with scores obtained in other community samples (eg, mean ASI score $21.85 \pm 10.14$ in reference 48). Correlations between average pain intensity across the four heat pain stimuli, anxiety sensitivity, fear of pain, pain catastrophizing, pain avoidance, alexithymia, and sex are presented in Table 1. Pain catastrophizing, pain avoidance, and sex were not significantly correlated with average pain intensity.

Relationship between alexithymia and average pain intensity after controlling for anxiety sensitivity, pain avoidance, fear of pain, pain catastrophizing, and sex

A two-step multiple linear regression analysis was used to test the relative contribution of alexithymia in predicting average pain intensity after controlling for sex and some of the factors in Turk's diathesis-stress model of chronic pain and disability. Results of the analyses are presented in Table 2.

First, fear of pain, anxiety sensitivity, pain avoidance, pain catastrophizing, and sex were entered in the regression analysis to create model 1 . Results indicated that these five variables together accounted for $27 \%$ of the variance in average pain 


\begin{tabular}{|c|c|c|c|c|c|}
\hline Variable & Beta & $\mathbf{P}$ & Total $\mathbf{R}^{2}$ & $\mathbf{R}^{2} \Delta$ & FA \\
\hline \multicolumn{6}{|l|}{ Step 1} \\
\hline \multicolumn{6}{|c|}{ Model 1: Components of Turk model } \\
\hline Summary & & & 0.270 & 0.270 & 4.502 \\
\hline FPQ-III & 0.454 & 0.001 & & & \\
\hline ASI & 0.069 & 0.593 & & & \\
\hline PASS-AVO & -0.009 & 0.946 & & & \\
\hline PCS & 0.049 & 0.706 & & & \\
\hline Sex & 0.294 & 0.015 & & & \\
\hline
\end{tabular}

Step 2: After controlling for components of Turk model Model 2A: Alexithymia

\begin{tabular}{lrllll}
\hline Final model & & & 0.352 & 0.083 & 7.642 \\
FPQ-III & 0.453 & 0.001 & & & \\
ASI & 0.012 & 0.922 & & & \\
PASS-AVO & -0.002 & 0.987 & & & \\
PCS & -0.025 & 0.841 & & & \\
Sex & 0.263 & 0.023 & & & \\
TAS-20 & 0.307 & 0.008 & & & \\
Model 2B-1: TAS-F1 - Difficulty identifying feelings & &
\end{tabular}

\begin{tabular}{|c|c|c|c|c|c|}
\hline Final model & & & 0.319 & 0.049 & 4.333 \\
\hline FPQ-III & 0.472 & 0.001 & & & \\
\hline ASI & -0.010 & 0.940 & & & \\
\hline PASS-AVO & 0.022 & 0.867 & & & \\
\hline PCS & -0.060 & 0.663 & & & \\
\hline Sex & 0.292 & 0.014 & & & \\
\hline TAS-F1 & 0.259 & 0.042 & & & \\
\hline \multicolumn{6}{|c|}{ Model 2B-2: TAS-F2 - Difficulty describing feelings } \\
\hline Final model & & & 0.370 & 0.100 & 9.541 \\
\hline FPQ-III & 0.475 & 0.000 & & & \\
\hline ASI & 0.019 & 0.876 & & & \\
\hline PASS-AVO & 0.030 & 0.818 & & & \\
\hline PCS & -0.002 & 0.987 & & & \\
\hline Sex & 0.315 & 0.006 & & & \\
\hline TAS-F2 & 0.324 & 0.003 & & & \\
\hline \multicolumn{6}{|c|}{ Model 2B-3: TAS-F3 - Externally oriented thinking } \\
\hline Final model & & & 0.289 & 0.019 & 1.612 \\
\hline FPQ-III & 0.433 & 0.002 & & & \\
\hline ASI & 0.076 & 0.554 & & & \\
\hline PASS-AVO & -0.039 & 0.780 & & & \\
\hline PCS & 0.055 & 0.668 & & & \\
\hline Sex & 0.250 & 0.045 & & & \\
\hline TAS-F3 & 0.148 & 0.209 & & & \\
\hline
\end{tabular}

Sex coded as 0 (female) and 1 (male). ASI Anxiety Sensitivity Index; FPQ-III Fear of Pain Questionnaire III; PASS-AVO Avoidance subscale of the Pain Anxiety Symptom Scale-20; PCS Pain Catastrophizing Scale; TAS-20 Toronto Alexithymia Scale-20; TAS-F1 Total score on the difficulty identifying feelings subscale of the TAS-20; TAS-F2 Total score on the difficulty describing feelings subscale of the TAS-20; TAS-F3 Total score on the externally oriented thinking subscale of the TAS-20

intensity $\left(F[5,61]=4.50 ; R^{2}=0.27 ; P=0.001\right)$. Fear of pain $(\beta=0.454 ; t=3.44 ; \mathrm{P}=0.001)$, and $\operatorname{sex}(\beta=0.294 ; t=2.49 ; \mathrm{P}=0.015)$ were the only significant predictors in model 1 .

In model 2A, alexithymia was entered separately after controlling for variables in model 1 . The overall model predicting average pain intensity was significant $\left(F[6,60]=5.43 ; R^{2}=0.35\right.$; $\mathrm{P}=0.008)$. Alexithymia $(\beta=0.31, t=2.76, \mathrm{P}=0.008)$, fear of pain $(\beta=0.45, t=3.61, P=0.001)$ and sex $(\beta=0.26, t=2.33, P=0.023)$ were the only three significant predictors of average pain intensity. Fear of pain and sex accounted for $20.0 \%$ and $6.8 \%$ of the variance, respectively; alexithymia accounted for an additional $9.6 \%$ of unique variance.

Further analyses were conducted to determine which aspects of alexithymia accounted for the observed relationship with average pain intensity. A series of three linear regression analyses were conducted. Each of the three subscales of the TAS-20 - difficulty identifying feelings (factor 1), difficulty describing feelings (factor 2), and externally oriented thinking (factor 3) - was entered in three separate models after controlling for variables in model 1. Results of these analyses are presented in Table 2. For all three models, the overall model predicting average pain intensity was significant (Factor 1: $\mathrm{F}[6,60]=4.68$, $\mathrm{R}^{2}=0.32, \mathrm{P}=0.001$; Factor 2 : $\mathrm{F}[6,60]=5.87, \mathrm{R}^{2}=0.37$, $\mathrm{P}<0.001$; Factor 3: $\left.\mathrm{F}[6,60]=4.06, \mathrm{R}^{2}=0.29, \mathrm{P}=0.002\right)$. In model 2B-1, fear of pain $(\beta=0.47, t=3.66, P=0.001)$, sex $(\beta=0.29, t=2.54, P=0.014)$, and difficulty identifying feelings $(\beta=0.26, t=2.08, P=0.042)$ were the only significant predictors of average pain intensity. In model $2 \mathrm{~B}-2$, fear of pain $(\beta=0.48, t=3.83, P<0.001)$, sex $(\beta=0.31, t=2.84$, $\mathrm{P}=0.006)$ and difficulty describing feelings $(\beta=0.32, t=3.09$, $\mathrm{P}=0.003)$ were the only significant predictors of average pain intensity. In model $2 \mathrm{~B}-3$, fear of pain $(\beta=0.43, t=3.27$, $\mathrm{P}=0.002)$ and $\operatorname{sex}(\beta=0.25, t=2.04, \mathrm{P}=0.045)$ were the only two predictors of average pain intensity. The externally oriented thinking subscale did not significantly predict average pain intensity $(\beta=0.15, t=1.27, \mathrm{P}=0.209)$.

Examining possible interactions among significant predictors of pain intensity

To examine whether fear of pain and alexithymia interacted to predict average pain intensity, a linear regression model was constructed that included the two variables and their interaction (multiplying the two variables after centering). The overall model significantly predicted average pain intensity $\left(F[3,63]=8.44 ; R^{2}=0.29 ; P<0.001\right)$. Fear of pain $(\beta=0.39$, $t=3.58, \mathrm{P}=0.001)$ and alexithymia $(\beta=0.35, t=3.12, \mathrm{P}=0.003)$ significantly predicted average pain intensity but the fear of pain $\times$ alexithymia interaction $\operatorname{did}$ not $(\beta=-0.02, t=-0.18$, $\mathrm{P}=0.86$ ), which suggests alexithymia and fear of pain are independent predictors of average pain intensity.

Similar analyses were conducted to examine whether fear of pain and alexithymia interacted with sex to predict average pain intensity. A linear regression model was constructed to include fear of pain, alexithymia, and sex, as well as the interactions between fear of pain and sex, and alexithymia and sex. The overall model significantly predicted average pain intensity $\left(F[5,61]=7.05 ; R^{2}=0.37 ; P<0.001\right)$. Fear of pain $(\beta=0.55$, $t=4.14, \mathrm{P}<0.001)$, sex $(\beta=0.25, t=2.30, \mathrm{P}=0.025)$ and alexithymia $(\beta=0.35, t=2.72, \mathrm{P}=0.008)$ significantly predicted average pain intensity but the interactions between fear of pain and sex $(\beta=-0.15, t=-1.07, P=0.290)$ and alexithymia and sex $(\beta=-0.04, t=-0.29, P=0.774)$ did not.

\section{DISCUSSION}

The purpose of the present study was to investigate what role, if any, alexithymia plays in predicting pain intensity ratings, relative to fear- and anxiety-based constructs outlined in Turk's 
diathesis-stress model (24) and commonly assessed in the pain literature. The results indicate pain catastrophizing, anxiety sensitivity, pain avoidance, fear of pain, and alexithymia accounted for $35 \%$ of the variance in average heat pain ratings. Fear of pain, sex, and alexithymia were the only significant predictors in the final regression model, accounting for $20.0 \%$, $6.8 \%$, and $9.6 \%$ of unique variance, respectively. Follow-up analyses failed to find a significant interaction between fear of pain and alexithymia, or between sex and fear of pain, or sex and alexithymia, indicating that these variables independently predict heat pain ratings. Additional analyses found the difficulty identifying feelings and difficulty describing feelings subscales of the TAS-20 were significant predictors of average heat pain ratings, while the externally oriented thinking subscale was not.

The present study is the first to measure both fear of pain and alexithymia in participants undergoing heat pain stimulation. The results are consistent with previous research examining the relationships between pain and fear of pain, and pain and alexithymia. Research has shown a significant positive correlation between alexithymia and pain ratings in healthy subjects during medical procedures $(8,49)$ and in response to experimentally induced pain $(7,9)$. Alexithymia has also been shown to correlate positively with pain severity, after controlling for depressed mood, in patients with painful temporomandibular disorder (50). Research also demonstrates a significant association between the minor pain subscale of the FPQ-III and pain intensity scores during an ischemic pain test, as well as an association between FPQ-III total scores and pain tolerance during electrical stimulation and thermal pain testing (51). High fear of pain, as measured by a Dutch version of the FPQ, has also been associated with increased cold pressor pain ratings (52).

The results of the present study indicate both fear of pain and alexithymia predict pain intensity ratings to thermal stimuli between $46^{\circ} \mathrm{C}$ and $49^{\circ} \mathrm{C}$. Numerous studies have documented a link between alexithymia and over-reporting of physical symptoms (10), as well as physical illness, including chronic pain $(50,53,54)$. Lumley et al $(55)$ suggest individuals with alexithymia may experience physiological hyperarousal and a biased perception and reporting of somatic sensations, leading to increased physical illness. Alexithymia correlates significantly with measures of somatosensory amplification $(56,57)$, lower tolerance to painful electrical stimulation (7), and is associated with higher baseline levels of sympathetic activity (55). In the present study, individuals with higher scores on the TAS-20 may have had a tendency to be excessively aware of or attentive to their bodies, relative to individuals with lower scores, resulting in amplified pain experiences and/or pain ratings in response to the unpleasant thermal stimulation. It is also possible, however, that individuals with higher TAS-20 scores have lower thresholds to painful stimuli reflecting a difference at an earlier phase of sensory processing (eg, at the spinal cord level). Future research may consider using the nociceptive flexion reflex paradigm (58) to help distinguish between these two possibilities. The nonsignificant interactions between sex and fear of pain and sex and alexithymia suggest that the influence of the latter two on pain intensity ratings was not due to a sex effect.

Hypervigilance to bodily sensations may also account for the relationship observed between fear of pain scores and heat pain ratings. Fear-avoidance models of chronic pain suggest that individuals who interpret pain as threatening may experience increased fear of pain, which may, in turn, promote a hypervigilance to body sensations, among other responses such as avoidance and guarding behaviours $(39,59)$.

Interestingly, pain catastrophizing, pain avoidance, and anxiety sensitivity were not significant predictors of heat pain intensity ratings in the present study. One possible explanation for the lack of a significant association between catastrophizing and pain ratings is that catastrophizing, as measured by the PCS, may differ from actual catastrophizing experienced during experimental pain testing. Studies examining the administration of a standardized questionnaire, such as the PCS, and measures of catastrophizing in vivo during pain testing have found only a moderate correlation between in vivo catastrophizing and PCS scores $(\mathrm{r}=0.46)$. Moreover, only in vivo catastrophizing, and not PCS scores, correlated with cold pressor pain ratings and pain tolerance $(49,60)$.

The lack of a significant association between pain avoidance and average pain intensity suggests pain avoidance responses, as measured by the PASS-AVO, which was designed to measure avoidance in the context of chronic pain, may not generalize to avoidance behaviours in the context of acute experimental pain. Anxiety sensitivity also did not have a significant direct effect on heat pain ratings. However, this does not rule out the possibility that anxiety sensitivity had an indirect effect on pain ratings through its relationship with alexithymia and/or fear of pain. Anxiety sensitivity has been shown to correlate with higher sensory pain ratings in experimental settings (61-63), as well as with fear of pain (14,38,64-66) and alexithymia $(67,68)$.

It is important to note that the present study had a limited number of participants $(n=7)$ with alexithymia scores in the clinical range. Therefore, caution should be taken in generalizing the present results to individuals with alexithymia. Furthermore, the present study focused on pain-free undergraduate university students; the relationships between alexithymia and the variables in Turk's diathesis-stress model may differ in individuals with chronic pain. Future research exploring the relationships among fear of pain, alexithymia, and pain perception in individuals with clinical levels of alexithymia and/or chronic pain will help further elucidate the relationship among these variables.

\section{SUMMARY}

Individuals who fear pain or have difficulty describing and identifying emotions reported greater pain intensity to thermal stimulation. These findings add to the growing body of literature linking alexithymia to pain and suggest that difficulties with emotion regulation, either through reduced emotional awareness via alexithymia or heightened emotional awareness via fear of pain, may negatively impact the pain experience.

ACKNOWLEDGEMENTS: The present study was supported in part by infrastructure grants from the Canadian Foundation for Innovation and the Ontario Innovation Trust. JK is supported by a Canadian Institutes of Health Research (CIHR) Canada Research Chair in Health Psychology at York University. MGP is supported by a CIHR Canada Graduate Masters Award. ALM is supported by a CIHR Doctoral Award. MGP and ALM are Strategic Training Fellows in Pain: Molecules to Community. 


\section{REFERENCES}

1. Haviland MG, Hendryx MS, Cummings MA, Shaw DG, MacMurray JP. Multidimensionality and state dependency of alexithymia in recently sober alcoholics. J Nerv Ment Dis 1991;179:284-90.

2. Hendryx MS, Haviland MG, Shaw DG. Dimensions of alexithymia and their relationships to anxiety and depression. J Pers Assess 1991;56:227-37.

3. Taylor GJ, Bagby RM, Parker JD. The alexithymia construct. A potential paradigm for psychosomatic medicine. Psychosomatics 1991;32:153-64.

4. Nemiah JC, Freyberger H, Sifneos PE. Alexithymia: A view of the psychosomatic process. In: Hill OW, ed. Modern Trends in Psychosomatic Medicine. London: Butterworths, 1976:430-9.

5. Salminen JK, Saarijärvi S, Äärelä E. Two decades of alexithymia. J Psychosom Res 1995;39:803-7.

6. Kreitler S, Niv D. Pain and alexithymia: The nature of a relation. The Pain Clinic 2001;13:13-38.

7. Nyklicek I, Vingerhoets AJ. Alexithymia is associated with low tolerance to experimental painful stimulation. Pain 2000;85:471-5.

8. Putterman E, Byrne N, Ditto B. Alexithymia and symptom reporting following blood donation. Psychosom Med 2001;63:138-9.

9. Sivik T. Alexithymia and hypersensitivity to touch and palpation. Integr Psychol Behav Sci 1993;28:130-6.

10. Byrne N, Ditto B. Alexithymia, cardiovascular reactivity, and symptom reporting during blood donation. Psychosom Med 2005;67:471-5.

11. Asmundson GJG, Norton PJ, Vlaeyen JWS. Fear-avoidance models of chronic pain: An overview. In: Asmundson GJG, Vlaeyen WS, Crombez G, eds. Understanding and Treating Fear of Pain. New York: Oxford University Press Inc, 2004:3-24.

12. Melzack R. From the gate to the neuromatrix. Pain 1999;(Suppl 6):S121-6.

13. Merskey H, Bogduk N. Classification of Chronic Pain: Descriptions of Chronic Pain Syndromes and Definitions of Pain Terms, 2nd edn. IASP Press, 1994.

14. Asmundson GJG, Norton GR. Anxiety sensitivity in patients with physically unexplained chronic back pain: A preliminary report. Behav Res Ther 1995;33:771-7.

15. Klages U, Kianifard S, Ulusoy O, Wehrbein H. Anxiety sensitivity as predictor of pain in patients undergoing restorative dental procedures. Community Dent Oral Epidemiol 2006;34:139-45.

16. Fritz JM, George SZ. Identifying psychosocial variables in patients with acute work-related low back pain: The importance of fearavoidance beliefs. Phys Ther 2002;82:973-83.

17. Klenerman L, Slade PD, Stanley IM, et al. The prediction of chronicity in patients with an acute attack of low back pain in a general practice setting. Spine 1995;20:478-84.

18. Linton SJ. A review of psychological risk factors in back and neck pain. Spine 2000;25:1148-56.

19. Roelofs J, Peters ML, Patijn J, Schouten EGW, Vlaeyen JWS. Electronic diary assessment of pain-related fear, attention to pain, and pain intensity in chronic low back pain patients. Pain 2004;112:335-42.

20. Samwel HJ, Kraaimaat FW, Crul BJ, Evers AW. The role of fearavoidance and helplessness in explaining functional disability in chronic pain: A prospective study. Int J Behav Med 2007;14:237-41.

21. Woby SR, Watson PJ, Roach NK, Urmston M. Are changes in fearavoidance beliefs, catastrophizing, and appraisals of control, predictive of changes in chronic low back pain and disability? Eur J Pain 2004;8:201-10.

22. Granot M, Ferber SG. The roles of pain catastrophizing and anxiety in the prediction of postoperative pain intensity: A prospective study. Clin J Pain 2005;21:439-45.

23. Severeijns RMS, Vlaeyen JWSPD, van den Hout MAPD, Weber WEJPD. Pain catastrophizing predicts pain intensity, disability, and psychological distress independent of the level of physical impairment. Clin J Pain 2001;17:165-72.

24. Turk DC. A diathesis-stress model of chronic pain and disability following traumatic injury. Pain Res Manage 2002;7:9-19.

25. Leeuw M, Goossens M, Linton S, Crombez G, Boersma K, Vlaeyen J. The fear-avoidance model of musculoskeletal pain: Current state of scientific evidence. J Behav Med 2007;30:77-94.

26. Lumley MA, Smith JA, Longo DJ. The relationship of alexithymia to pain severity and impairment among patients with chronic myofascial pain: Comparisons with self-efficacy, catastrophizing, and depression. J Psychosom Res 2002;53:823-30.
27. Watson PJ, Latif RK, Rowbotham DJ. Ethnic differences in thermal pain responses: A comparison of South Asian and White British healthy males. Pain 2005;118:194-200.

28. Reiss S, Peterson RA, Gursky DM, McNally RJ. Anxiety sensitivity, anxiety frequency and the prediction of fearfulness. Behav Res Ther 1986;24:1-8.

29. Zinbarg RE, Barlow DH, Brown TA. Hierarchical structure and general factor saturation of the Anxiety Sensitivity Index: Evidence and implications. Psychol Assess 1997;9:277-84.

30. Rodriguez BF, Bruce SE, Pagano ME, Spencer MA, Keller MB. Factor structure and stability of the Anxiety Sensitivity Index in a longitudinal study of anxiety disorder patients. Behav Res Ther 2004;42:79-91.

31. Keefe FJ, Brown GK, Wallston KA, Caldwell DS. Coping with rheumatoid arthritis pain: Catastrophizing as a maladaptive strategy. Pain 1989;37:51-6.

32. Sullivan MJ, Thorn B, Haythornthwaite JA, et al. Theoretical perspectives on the relation between catastrophizing and pain. Clin J Pain 2001;17:52-64.

33. Sullivan MJL, Bishop SR, Pivik J. The pain catastrophizing scale: Development and validation. Psychol Assess 1995;7:524-32.

34. Osman A, Barrios FX, Gutierrez PM, Kopper BA, Merrifield T, Grittmann L. The Pain Catastrophizing Scale: Further psychometric evaluation with adult samples. J Behav Med 2000;23:351-65.

35. McCracken LM, Dhingra L. A short version of the Pain Anxiety Symptoms Scale (PASS-20): Preliminary development and validity. Pain Res Manage 2002; 7:45-50.

36. McCracken LM, Zayfert C, Gross RT. The pain anxiety symptoms scale: Development and validation of a scale to measure fear of pain. Pain 1992;50:67-73.

37. Abrams MP, Carleton RN, Asmundson GJ. An exploration of the psychometric properties of the PASS-20 with a nonclinical sample. J Pain 2007;8:879-86.

38. Asmundson GJG, Taylor S. Role of anxiety sensitivity in painrelated fear and avoidance. J Behav Med 1996;19:577-86.

39. Norton PJ, Asmundson GJG. Amending the fear-avoidance model of chronic pain: What is the role of physiological arousal? Behav Ther 2003;34:17-30.

40. McNeil DW, Rainwater AJ. Development of the Fear of Pain Questionnaire-III. J Behav Med 1998;21:389-410.

41. Taylor GJ, Bagby RM. New trends in alexithymia research. Psychother Psychosom 2004;73:68-77.

42. Bagby RM, Parker JDA, Taylor GJ. The twenty-item Toronto Alexithymia Scale-I. Item selection and cross-validation of the factor structure. J Psychosom Res 1994;38:23-32.

43. Parker JDA, Taylor GJ, Bagby RM. The 20-Item Toronto Alexithymia Scale: III. Reliability and factorial validity in a community population. J Psychosom Res 2003;55:269-75.

44. Katz J, Melzack R. Measurement of pain. Surg Clin North Am 1999;79:231-52.

45. Bijur PE, Latimer CT, Gallagher EJ. Validation of a verbally administered Numerical Rating Scale of acute pain for use in the emergency department. Acad Emerg Med 2003;10:390-2.

46. Williamson A, Hoggart B. Pain: A review of three commonly used pain rating scales. J Clin Nurs 2005;14:798-804.

47. Taylor GJ. The alexithymia construct: Conceptualization, validation, and relationship with basic dimensions of personality. New Trends Exp Clin Psychiatry 1994;10:61-74.

48. Schmidt NB, Joiner TE. Structure of the Anxiety Sensitivity Index psychometrics and factor structure in a community sample. J Anxiety Disord 2002;16:33-49.

49. Dixon KE, Thorn BE, Ward LC. An evaluation of sex differences in psychological and physiological responses to experimentally-induced pain: A path analytic description. Pain 2004;112:188-96.

50. Glaros AG, Lumley MA. Alexithymia and pain in temporomandibular disorder. J Psychosom Res 2005;59:85-8.

51. Roelofs J, Peters ML, Deutz J, Spijker C, Vlaeyen JWS. The Fear of Pain Questionnaire (FPQ): Further psychometric examination in a non-clinical sample. Pain 2005;116:339-46.

52. Roelofs J, Peters ML, van der Zijden M, Vlaeyen JWS. Does fear of pain moderate the effects of sensory focusing and distraction on cold pressor pain in pain-free individuals? J Pain 2004;5:250-6.

53. Lumley MA, Asselin LA, Norman S. Alexithymia in chronic pain patients. Compr Psychiatry 1997;38:160-5. 
54. Mehling WE, Krause N. Are difficulties perceiving and expressing emotions associated with low-back pain? The relationship between lack of emotional awareness (alexithymia) and 12-month prevalence of low-back pain in 1180 urban transit operators. J Psychosom Res 2005;58:73-81.

55. Lumley MA, Stettner L, Wehmer F. How are alexithymia and physical illness linked? A review and critique of pathways. J Psychosom Res 1996;41:505-18

56. Nakao M, Barsky AJ, Kumano H, Kuboki T. Relationship between somatosensory amplification and alexithymia in a Japanese psychosomatic clinic. Psychosomatics 2002;43:55-60.

57. Wise TN, Mann LS. The relationship between somatosensory amplification, alexithymia, and neuroticism. J Psychosom Res 1994:38:515-21.

58. France CR, France JL, al'Absi M, Ring C, McIntyre D. Catastrophizing is related to pain ratings, but not nociceptive flexion reflex threshold. Pain 2002;99:459-63.

59. Vlaeyen JWS, Linton SJ. Fear-avoidance and its consequences in chronic musculoskeletal pain: A state of the art. Pain 2000;85:317-32.

60. Edwards RR, Campbell CM, Fillingim RB. Catastrophizing and experimental pain sensitivity: Only in vivo reports of catastrophic cognitions correlate with pain responses. J Pain 2005;6:338-9.
61. Jones A, Zachariae R. Investigation of the interactive effects of gender and psychological factors on pain response. Br J Health Psychol 2004;9:405-18.

62. Keogh E, Birkby J. The effect of anxiety sensitivity and gender on the experience of pain. Cogn Emot 1999;13:813-29.

63. Keogh E, Cochrane M. Anxiety sensitivity, cognitive biases, and the experience of pain. J Pain 2002;3:320-9.

64. Martin AL, McGrath PA, Brown SC, Katz J. Anxiety sensitivity, fear of pain and pain-related disability in children and adolescents with chronic pain. Pain Res Manage 2007;12:267-72.

65. Muris P, Vlaeyen J, Meesters C. The relationship between anxiety sensitivity and fear of pain in healthy adolescents. Behav Res Ther 2001;39:1357-68.

66. Zvolensky MJ, Goodie JL, McNeil DW, Sperry JA, Sorrell JT. Anxiety sensitivity in the prediction of pain-related fear and anxiety in a heterogeneous chronic pain population. Behav Res Ther 2001;39:683-96.

67. Devine H, Stewart SH, Watt MC. Relations between anxiety sensitivity and dimensions of alexithymia in a young adult sample theory, research, and treatment of the fear of anxiety. J Psychosom Res 1999;47:145-58.

68. Mueller J, Alpers GW. Two facets of being bothered by bodily sensations: Anxiety sensitivity and alexithymia in psychosomatic patients. Compr Psychiatry 2006;47:489-95. 


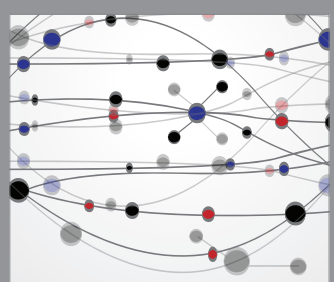

The Scientific World Journal
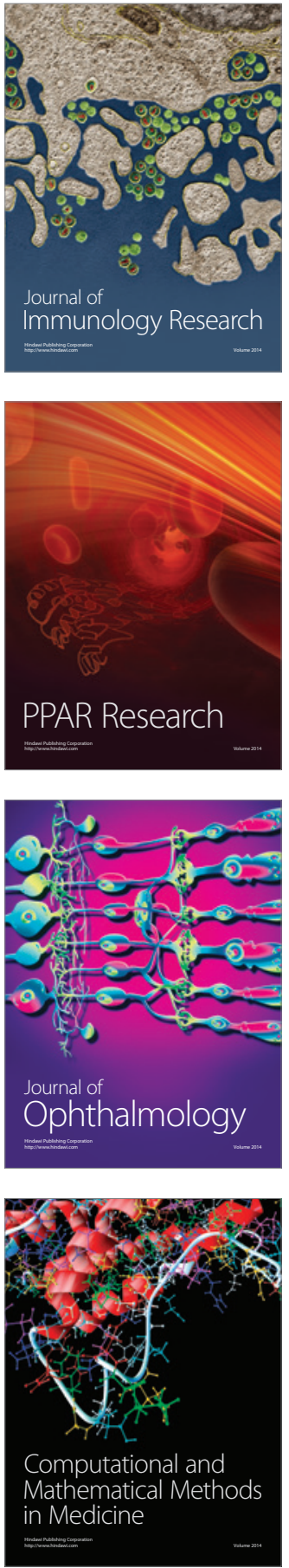

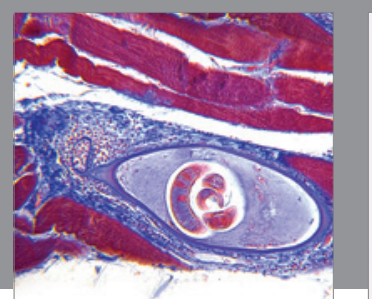

Gastroenterology Research and Practice

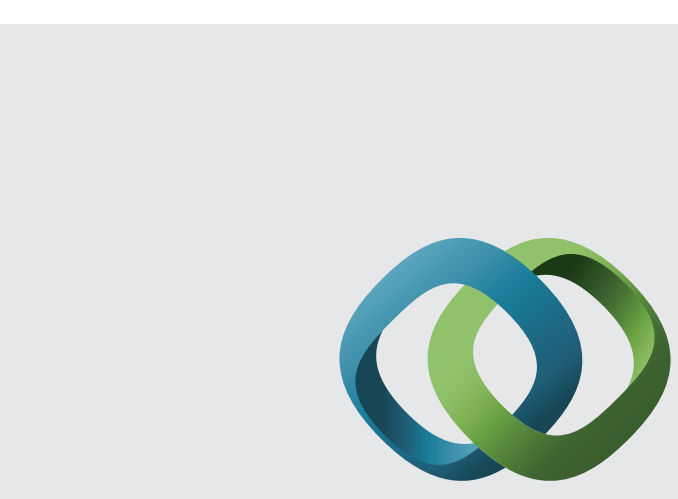

\section{Hindawi}

Submit your manuscripts at

http://www.hindawi.com
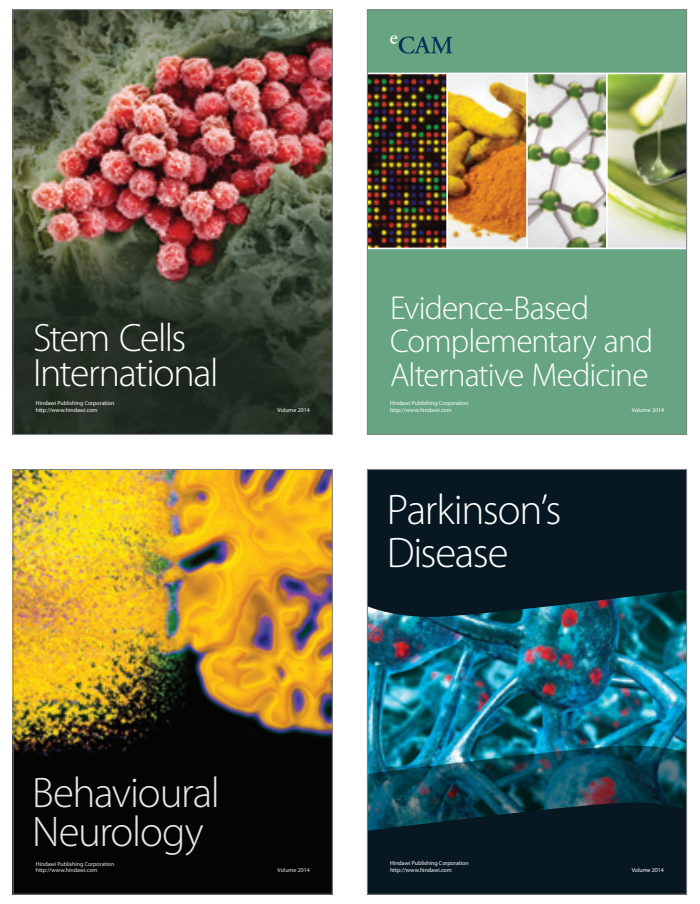
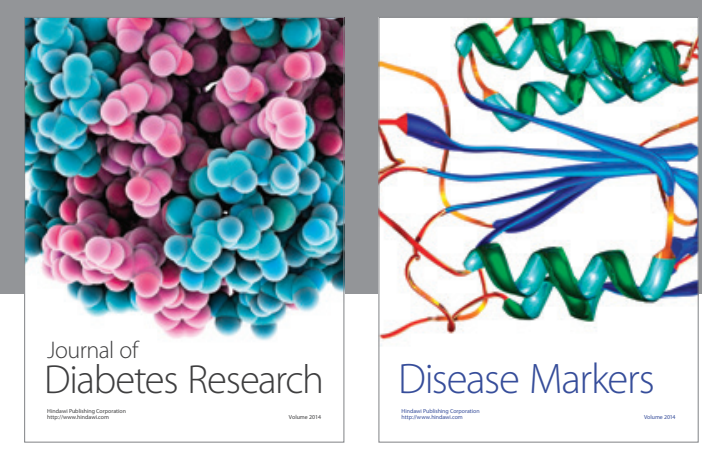

Disease Markers
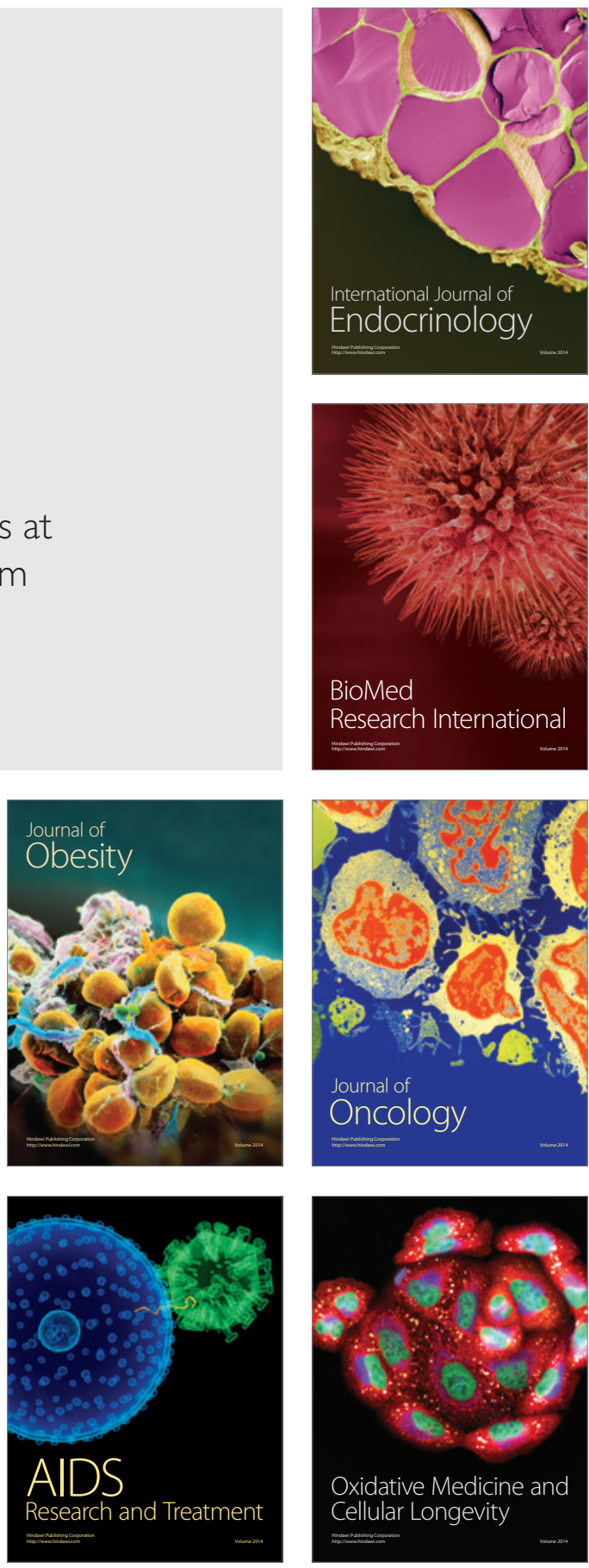